\title{
Necrópolis y lugares de enterramiento rurales de época romana en la provincia de Córdoba*
}

\author{
Gloria Galeano CuencA**
}

\section{A) ANÁLISIS DE LOS DATOS}

Las distintas investigaciones que se llevan a cabo sobre la religiosidad rural en época romana manifiestan, en lo que a la provincia de Córdoba se refiere, una carencia fundamental: la necesidad de un estudio del mundo funerario de época romana en esta zona. La mayoría de las referencias con que contamos o bien son orales o bien se limitan a escasos datos bibliográficos. Nosotros, a raíz de las mismas, vamos a intentar reconstruir los rasgos generales del mundo funerario romano en el ámbito rural de nuestra provincia ${ }^{1}$.

En primer lugar hay que tener en cuenta que de las ciento treinta y dos referencias que incluimos en el catálogo, setenta y seis hacen alusión a necrópolis o posibles áreas de necrópolis lo que supone un $57,57 \%$ del total; treinta y cinco a tumbas halladas agrupadas en un zona concreta, es decir, un $26,51 \%$; siete a tumbas completamente aisladas lo cual viene a representar el $5,3 \%$; diez sepulcros $(7,57 \%)$; los sarcófagos aislados, es decir, aquellos que se encuentran fuera de todo contexto funerario se reducen a un $1,51 \%$, frente a los que si se contextualizan en un ámbito fu-

* Hemos realizado un estudio general sobre esta temática en: Galeano CuEnCA, G.: Costumbres religiosas y prácticas funerarias romanas. Estudio del mundo rural en la provincia de Córdoba. Servicio de Publicaciones y Área de Historia Antigua de la Universidad de Córdoba (en prensa).

** Departamento de Historia Antigua. Universidad de Córdoba.

1 Debemos señalar, sin embargo, que esta carencia se ha visto en gran medida paliada por el reciente trabajo de Silvia Carmona Berenguer, anteriormente mencionado. Pero, a pesar de ello, sigue siendo necesaria una visión general de la época romana -su trabajo se centra en el período tardoantiguo - que nos ayude a establecer límites, tanto cronológicos como espaciales y sociales. 
nerario claro suponen el $2,27 \%$. De todas estas noticias treinta y tres se limitan a dar el dato, es decir, simplemente se aporta el conocimiento de que en un lugar determinado existen una serie de restos interpretados como conjunto de tumbas o posibles necrópolis, pero sin especificar ningún otro aspecto, ni tipología de los enterramientos, ni rito empleado, ni materiales hallados, ni vinculación a algún tipo de hábitat ni por supuesto cronología. En consecuencia, esas treinta y tres referencias, que suponen un $25 \%$ del total, hemos tenido que excluirlas de los datos que aportamos a continuación.

\section{Emplazamientos}

La mayoría de las áreas o zonas funerarias se sitúan en llano o en la ladera de un monte o cerro, en cuya cima posiblente estuviese emplazado el núcleo de habitación al que pertenecerían las mismas. Cabe destacar que un buen porcentaje de estas áreas funerarias aparecen asociadas a villae, esto sucede en veintinueve casos a los que habría que añadir los cuatro en los que el hábitat parece ser de un poblado o asentamiento de mayor entidad que una villa, lo cual supone un $21,96 \%$; de ellas, veintitres son necrópolis y cuatro hacen referencia a grupos de tumbas que posiblemente formen parte de una necrópolis aún sin constatar; el resto se corresponde con una tumba aislada, dos sepulcros y dos sarcófagos. Tanto los sepulcros como el sarcófago hacen alusión, a nuestro entender, al recinto funerario del dueño de la villa. Por su parte, la tumba aislada puede hacer referencia al mismo caso o a cualquier enterramiento de un habitante de la villa, incluso pudieramos estar ante una zona de necrópolis sin descubrir.

En cuanto a la ubicación en las proximidades de una vía o camino debemos decir que carecemos de datos suficientes para establecer una tónica general de comportamiento pues, aunque conocemos que en trece de los casos, nueve necrópolis, tres grupos de tumbas y una tumba aislada, se encuentran en las proximidades de vías, del resto no tenemos referencias sobre esta relación. Sin embargo, en este sentido, el mapa de dispersión de los emplazamientos funerarios nos aporta una serie de datos complementarios; podemos observar cómo el número de emplazamientos que se encuentran en zonas próximas o muy próximas a vías romanas es mucho mayor, y si a ello añadimos que en el mapa sólo reflejamos las vías principales de comunicación, obviando los caminos de importancia 
menor, que sin duda debieron existir, obtenemos que casi el cien por cien de los núcleos de carácter funerario pueden ser puestos en conexión con alguna vía o camino, cumpliéndose así una de las normas romanas en cuanto a la ubicación de este tipo de núcleos se refiere. Por otro lado, destaca también el hecho de que estos ámbitos de carácter funerario parecen situarse próximos unos a otros.

\section{Tipología de las sepulturas}

En líneas generales nos encontramos, en la mayoría de los casos, con fosas excavadas en la tierra, piedra o como mucho en la roca, hecho constatado en tan sólo una ocasión ${ }^{2}$. Son raras las sepulturas que presentan revestimiento interno, pero cuando se produce esta circunstancia dicho revestimiento es de lajas de piedra o de ladrillo, generalmente limitado a la zona de la cabecera, como sucede en algunas de las tumbas de las necrópolis de «El Ochavillo» (Hornachuelos), «El Ruedo» (Almedinilla) o «Los Molinillos» (Baena). Como cubiertas se emplean materiales diversos: losas de piedra, generalmente caliza micrítica ("Los Molinillos") o miocénica («El Ochavillo»), aunque también se usa la arcilla; tégulas y lápidas, como en «Reynilla» o «El Ruedo» 3; en raras ocasiones se utiliza el ladrillo y cuando se hace aparece reforzando a las losas de piedra. De todas ellas tres son cistas, una de las cuales estaba cubierta por una losa de piedra y albergaba un sarcófago, también en piedra, mientras las otras dos pertenecían a sendas necrópolis; y las dos restantes se corresponden con la forma de campana "a caisson». Por último, señalar que en la necrópolis de «Los Molinillos» (Baena) las cubiertas se sellan con opus signinum, mientras en el resto de emplazamientos no se ha connstatado ningún material que sirviese de unión.

Menos comunes son los sepulcros. De los siete que hemos recogido tenemos datos de cinco de ellos mientras que de los dos restantes carecemos de información significativa. En general estos datos son escasos lo cual supone un problema al que habría que añadir la variedad en su tipología. Por ello, las características que recogemos, en mọdo alguno, deben

2 Como señala S. CARMONA: op. cit., p. 91, estos casos hay que matizarlos, pues pueden adscribirse a un período cronológico posterior: siglo IX con perduraciones hasta el siglo XII.

3 Carmona Berenguer, S.: op. cit., p. 92; en el caso de aEl Ruedo" este tipo de cubierta se ha datado en los primeros momentos de la necrópolis, finales del siglo fll y siglo IV d.C. 
considerarse como tónica general dentro de los sepulcros pertenecientes al mundo rural. Nos hemos encontrado, por un lado, con un tipo de sepulcro concebido para albergar la caja o sarcófago del difunto, que en los dos casos constatados resulta estar realizada en plomo. Estos sepulcros presentan una cubierta abovedada formada a base de ladrillos. Por otro lado, tenemos un tipo de construcción semisubterránea que ha sido interpretada como el sepulcro del propietario de alguna villa ${ }^{4}$. Cabe destacar que de los siete sepulcros tres han conservado el epígrafe correspondiente, es decir, estamos ante los sepulcros de Memmia Marciana, L. Caesius Helenus, P. Cornelius Primus y Fabia Fabiana.

En cuanto a las urnas cinerarias tan sólo hemos recogido la existencia de cuatro: una caja de plomo perteneciente a uno de los sepulcros anteriores, una urna de vidrio protegida por una caja de plomo y de las otras dos carecemos de datos.

\section{Orientación}

En estas necrópolis o grupos de tumbas debió existir una disposición ordenada formando calles o hileras como se constata en las necrópolis de "El Ochavillo», "El Ruedo" o "Reynilla». La ausencia de información en este sentido nos impide establecer una comparación por zonas y épocas, pero creemos que tal disposición debió producirse en la mayoría de los casos que presentamos o, cuando menos, una tendencia hacia dicha ordenación. Las propias tumbas, en aquellas necrópolis que han sido estudiadas presentan una orientación preferente de Norte-Sur, aunque también se constata la orientación hacia el Este.

\section{Ritual}

El rito empleado es, mayoritariamente, el de la inhumación. De las noventa y siete referencias, cincuenta y siete aluden a su uso frente a las cinco que mencionan expresamente la incineración; del resto carecemos de noticias sobre el rito que se practicó.

4 Sobre la descripción del mismo Ver supra. Una descripción más completa puede hallarse en lacort Navarro, P.J.: Monturque en la época romana. Córdoba, 1994, pp. 47-49. 
En función de los escasos datos con que contamos sólo podemos afirmar que en época tardorromana el cadáver era enterrado en posición decúbito supino, con los brazos generalmente extendidos situados a lo largo del cuerpo o bien sobre la pelvis, aunque también aparecen cadáveres con los brazos cruzados sobre el pecho; la cabeza suele estar de frente $u$ orientada hacia el lugar en que se orienta la propia tumba, a veces aparece girada a derecha o izquierda.

La reutilización de los enterramientos también parece constituirse en tónica general, pues en las necrópolis estudiadas son escasas las tumbas simples, constituyendo un porcentaje más elevado las doble, triples, cuádruples y los osarios (estos últimos no son muy abundantes) constatados en la necrópolis de "El Ruedo». Las tumbas dobles y triples parecen ser más frecuentes entre los enterramientos infantiles mientras la reutilización es más común entre los adultos como se aprecia en la necrópolis de Reynilla, donde de las once excavadas, todas excepto una mostraban un segundo cadáver en posición decúbito supino y los restos del primero a los pies, en ocasiones la cabeza se dejaba al nivel del segundo.

Por otro lado, en los artículos, informes y referencias orales con las que hemos contado no se constata la existencia de clavos en el interior de las tumbas, salvo en algún caso, como en «El Ruedo», lo cual nos hace suponer que el difunto era enterrado envuelto en un sudario o bien desnudo, es decir, sin ataud, aunque esto habría que afirmarlo con ciertas reservas porque existe la posibilidad de que no se empleen clavos en la realización de los ataudes, al menos, de una forma generalizada.

La constatación en el interior de las sepulturas de una moneda, circunstancia que se produce en el sepulcro del Arroyo del Plomo (Baena), puede estar indicando que el difunto pudo ser enterrado con ella en la boca, algo frecuente en Roma y que era un símbolo y un medio para que el difunto pudiese «pagar la barca de Caronte», en «El Ruedo», una de las monedas se recogió a la altura media del cadáver, por lo cual, la posible simbología que hemos apuntado quizás deba descartarse y pensar más en el empleo de la misma como objeto de adorno formando parte de la vestimenta o con alguna otra utilización ${ }^{5}$.

5 En este sentido pueden resultar significativos los trabajos de ALFARO, C: «Uso no monetal de algunas monedas púnicas de la Península Ibérica», $R I N, X C V, 1993$, pp. 261-276; y, PERA, RoselLA: «La moneta antica come talismano», RIN, XVC, 1993, pp. 347-361. 
Dentro del ritual también cabe señalar la existencia de unas zonas para ofrendas que Carmona Berenguer recoge en «El Ruedo" ${ }^{6}$ y que pudieran haber existido en otras necrópolis, hoy destruidas, a tenor de los restos que se describen entre los que se menciona la existencia de lucernas o vasos de cerámica romana.

El rito incineratorio es menos frecuente según puede deducirse de los datos que hemos podido recoger, pero debemos tener en cuenta que estos datos hacen referencia de forma mayoritaria a necrópolis bastante tardías, cuando la inhumación se había impuesto y que carecemos de noticias sobre necrópolis más tempranas, adscribibles al mundo rural ${ }^{7}$.

Dentro del ritual de la incineración las cenizas se solían contener en urnas que pueden ser de vidrio como la de Doña Rama (Belmez), en este caso protegida por una caja de plomo; en la propia caja de plomo como sucede en el sepulcro hallado en el llamado Arroyo del Plomo (T.m. de Baena); o en otra serie de recipientes de los cuales no quedan restos en el ámbito de nuestro estudio.

\section{Ajuares}

La aparición de ajuar en una tumba puede llegar a resultar de suma importancia para las conclusiones finales de un estudio. En este sentido S. Carmona ha establecido una división de la provincia de Córdoba en dos zonas principales, la parte Sur de la misma que se incluiría en, la denominada por ella, zona media de Andalucia y caracterizada por incluir yacimientos con depósito funerario y objetos de adorno personal, y la zona Norte que se corresponde con la Andalucía Occidental y presenta influencias meseteñas en los depósitos rituales.

En nuestro caso la constatación de la existencia de ajuar funerario en los enterramientos sólo ha sido posible en veinte ocasiones. En líneas generales, los ajuares se señalan por su pobreza ya que se limitan a jarritas de cerámica común situadas, comúnmente, al lado de la cabeza

Carmona Berenguer, S.: op. cit., p. 90 y ss.

Estos datos pueden ser contrastados con los que nos aportan algunas necrópolis vinculadas a núcleos urbanos como la de "Las Pozas" que presenta un amplio espectro cronológico y contiene enterramientos de incineración y de inhumación, o la de Espejo que, fechada en el siglo d.C., también combina ambos ritos. 
del difunto, aunque también han aparecido a la altura de la pelvis como en la tumba número 10 de la necrópolis de «Reynilla». Los recipientes de vidrio también son frecuentes, entre ellos aparecen vasos y algún ungüentario. En raras ocasiones estos objetos son de cerámica fina: terra sigillata.

Independientemente de estos depósitos rituales, a los difuntos también se les podía enterrar con joyas o algún otro elemento de carácter más personal. El primer caso es más frecuente en nuestro ámbito de estudio y se produce en casi todas las necrópolis constatadas, aunque dichas joyas también destacan por su pobreza ya que se limitan a pendientes, anillos o colgantes, generalmente de bronce. Destaca, sin embargo, la sortija de oro hallada en el sepulcro de Fabia Fabiana; aun así, los individuos enterrados con dichas joyaś parecen ser los de mayor nivel económico pues el resto aparecen sir ellas, como mucho se entierran con alguna jarra de cerámica común pero lo más frecuente es que carezcan de ajuar tanto personal como ritual. Además, se corresponden, al menos en los casos que hemos podido constatar con fosas mejor realizadas, es decir, no sólo excavadas en la tierra, sino que presentan recubrimiento interno de lajas de piedra o ladrillo y cubierta de losas; frente a ellas encontramos las de los individuos que carecen de todo tipo de ajuar y son enterrados en fosas con cubiertas que mezclan el ladrillo con las tégulas, como sucede en la necrópolis de «Reynilla». En el segundo de los casos, es decir, la presencia de objetos personales en la sepultura, éstos se limitan a espadas halladas en las tumbas de "Callejón de los Moros" (Cañete de las Torres); la barrita de plata hallada en la necrópolis de Llano Medina (Doña Mencía) que posiblemente servía para la manicura, o el espejo hallado en la Pava, que podría relacionarse con el carácter indígena del individuo enterrado en la tumba ${ }^{8}$

Sin embargo, debemos dejar constancia de que la diferencia que puede apreciarse en el tipo de ajuar, tanto ritual como personal, pero fundamentalmente el primero, está en estrecha relación con la secuencia cronológica y con el nivel socioeconómico de los individuos, como señala $S$. Carmona «estas sociedades rurales llegadas a nosotros a través de sus necrópolis se basan en una economía agropecuaria, mostrándose poco

8 Sobre este tema vid. BLÁZQUEZ MARTINEZ, J.Ma: "La aculturación en la religión indígena", Formas de difusión en la religión indígena. (II Encuentro-coloquio ARYS, Jarandilla de la Vera, dic. 1990), Madrid, 1993, pp. 35-74. 
jerarquizadas y con escasos recursos que quedan reflejados en los depósitos funerarios» 9 .

Por último, cabe señalar la progresiva desaparición de ajuares a lo largo de los siglos, es decir, se va perdiendo la costumbre de depositar junto al difunto un ajuar de carácter ritual, hecho que está en consonancia con lo sucedido en el resto del ámbito cultural romano ${ }^{10}$.

\section{Conclusiones}

El espectro cronológico aunque en principio pudiera parecer amplio - se constatan sepulturas desde el siglo । a.C. hasta el siglo $v$ d.C.-, no lo es tanto ya que la mayoría de los enterramientos debemos encuadrarlos entre el siglo III y el siglo $v$ d.C., es decir, en una época tardorromana, principalmente en el siglo IV d.C.. Esta circunstancia pudiera explicarse por dos factores fundamentales:

- Escasez de estudios en la provincia de Córdoba sobre el mundo rural en general $y$, en particular, sobre el mundo funerario en este ámbito.

- Escasez de necrópolis rurales en la época anterior al Bajo Imperio, lo cual explicaría la diferencia porcentual de los hallazgos.

Tampoco puede excluirse la posibilidad de coexistencia de enterramientos romanos con enterramientos ibéricos en lo que serían necrópolis comunes como se ha constatado en otras zonas.

Por otro lado, parece rastrearse un cambio de mentalidad que se manifiesta en la progresiva parquedad de los depósitos funerarios.

Finalmente, cabe destacar también el hecho de que la inhumación parece implantada definitivamente en el siglo II d.C. pues todos los datos con que contamos aluden a la incineración entre el siglo I a.C. y el siglo I d.C., mientras que a partir del siglo $\|$ d.C. no volvemos a encontrar ningún enterramiento en el que no se haya empleado la inhumación. Estos datos reflejan una temprana extensión de la inhumación, sobre todo, si tenemos en cuenta la tónica general del Imperio que suele ser de una convivencia de ambos ritos a lo largo de los siglos ॥-11 d.C. Algo similar sucede en la zona levanti-

Carmona Berenguer, S.: op. cit., p. 73.

10 VOLLMER, A.-LÓPEZ BORGOÑOZ, A.: «Nuevas consideraciones...», p. 368. 
na donde los estudios realizados por González Villaescusa para el País Valenciano muestran también una cronología temprana que el autor justifica por la presencia de un sustrato prerromano afecto a la inhumación ${ }^{11}$.

\section{B) CATÁLOGO}

A continuación presentamos el catálogo de necrópolis y posibles necrópolis que han aparecido en la provincia de Córdoba ${ }^{12}$. Se trata de una recopilación de todas las noticias a las que hemos tenido acceso sobre las mismas así como de todas aquellas tumbas aisladas o en pequeño número que han sido descubiertas, la mayoría de las veces, por el arado en el desarrollo de las tareas de acondicionamiento de los terrenos para el cultivo de los mismos. Por ello debemos aclarar que en la mayoría de las ocasiones se carece de un estudio de dichas apariciones, casi todas ya perdidas, y sólo se cuenta con la noticia oral de los descubridores o con breves notas acerca del hallazgo, pero se adolece de una carencia casi completa de estudios sobre los mismos, así como de excavaciones que aporten datos significativos, más allá del hallazgo o de la simple enumeración de los restos. Sin embargo, debemos señalar la reciente presentación de un trabajo sobre el mundo funerario tardoantiguo en el ámbito rural, centrado en Andalucía que pone de manifiesto algunos de estos problemas, realizando un revisión bibliográfica sobre el tema desde finales del siglo XIX hasta nuestros días, reflejando las carencias con las que debemos enfrentarnos a la hora de abordar un trabajo de estas características $\mathrm{y}$, principalmente, sistematizando los datos y aportando una división espacio-cronológica de la región estudiada ${ }^{13}$.

Por último, mencionar que el carácter rural de estas necrópolis viene determinado por su distanciamiento de un núcleo urbano ${ }^{14}$.

11 González Villaescusa, R.: «Monde des morts et monde des vivants en Pays Valencien (Hispania Tarraconensis)", Monde des morts, monde des vivants en Gaule rurale, p. 414; sobre las pervivencias indígenas en la Bética, vid: SÁEZ, P.: «Notas sobre pervivencias del elemento indígena en la Bética...», pp. 461-493.

12 En el catálogo incluimos todos aquellos enterramientos aislados, necrópolis y monumentos de carácter funerario de los que hemos tenido noticia a lo largo de nuestra investigación.

13 Carmona Berenguer, S.: El mundo funerario rural tardo-antiguo y de época visigoda en Andalucia. La necrópolis de «El Ruedo» (Almedinilla, Córdoba). (Tesis Doctoral, inédita). Córdoba, 1995.

14 lbid., p. 18, n. $^{\circ} 5$. 


\section{Adamuz}

- Necrópolis asociada a una villa romana en terrenos de Algallarín ${ }^{15}$.

- Necrópolis hallada en el Cortijo de la Dehesa Vieja ${ }^{16}$. Se trata de sepulturas de inhumación excavadas en la tierra ${ }^{17}$ que muestran un período de ocupación en dos fases: época tardorromana con tumbas de fosa simple cubiertas por losas de caliza de mediano y gran tamaño, con ajuar del cual sabemos que entre las piezas recuperadas se encuentra una jarrita $u$ olpe, un vaso de vidrio, unos aretes de bronce y una cuenta de collar, todo ello en la misma tumba (t. 5); en la t. 3 había un vaso de cuerpo globular con el cuello troncocónico; la segunda fase es de época medieval islámica. Se encuentra asociada a una vía principal ${ }^{18}$.

- Sepultura hallada en la finca de «La Indiana», al parecer con ajuar, de época tardorromana o visigótica ${ }^{19}$.

\section{Aguilar de la Frontera}

- Sepultura en la Cruz de Roque de Mora ${ }^{20}$.

\section{Alcaracejos}

- En el Cerro de «El Germo» ${ }^{21}$ aparecieron grandes losas y enterramientos, junto a otros materiales romanos como columnas, capiteles y la inscripción dedicada a Júpiter ${ }^{22}$. Se asocia a una vía de carácter secundario y también a una basílica ${ }^{23}$.

15 VAQUERIzO GIL, D. et alli: «Adamuz», Los pueblos de Córdoba, I, p. 2.

16 RUIz NIETO, E.: «Intervención arqueológica de urgencia en el trazado del gaseoducto Sevilla-Madrid...", AAA, III, †990, p. 63.

17 El suelo tenía en su composición una alta concentración caliza lo que repercutió en la conservación de los restos óseos.

18 Carmona Berenguer, S.: op. cit., p. 90.

19 VAquerizo, D. et alli: "Adamuz», Los pueblos de Córdoba, I, p. 2.

20 Idem, «Aguilar de la Frontera», Los pueblos de Cordoba, 1, p. 23.

21 FITA, F.: «Alcaracejos...», p. 566. UlBERT, : «El Germo. Kirche und Profanbau aus dem frühen 7 Jahrhundert», $M M, 9,1968$, pp. 328-398.

22 Ver supra $n .^{\circ} 1$.

23 Carmona Berenguer, S.: op. cit., p. 90. 
Almedinilla

- Posible necrópolis ${ }^{24}$ de inhumación de época tardorromana o visigótica situada en el lugar llamado Barranco del Lobo ${ }^{25}$.

- Necrópolis romana de inhumación posiblemente asociada a una villa. Hallada en el paraje conocido como La Esperilla ${ }^{26}$ estaba parcialmente desmontada para la construcción de la carretera que une el pueblo con Fuente Grande en el límite de Granada, a la altura del km. 4, en el corte de la cuneta se veían restos de unos 6 enterramientos. Se trata de fosas de piedra y/o tégulas. Algunas contenían ajuar al parecer los vecinos del pueblo afirmaban que había platos de Terra sigillata.

- Necrópolis de «El Ruedo" ${ }^{27}$ asociada a una villa romana ${ }^{28}$. Situada en la ladera SE de la Sierra de los Judíos a unos $700 \mathrm{~m}$. sobre el nivel dél mar. Se desconoce su extensión real. Se excavaron más de 100 tumbas que en líneas generales consistían en fosas individuales, dobles, triples y osarios que responden a las siguientes características: individuos colocados en posición decúbito supino con brazos y piernas extendidos; cubiertas de tres tipos fundamentales: losas de piedra caliza toscamente escuadradas, calzadas con piedras más pequeñas, cerámica de almacenamiento, tégulas y ladrillos; las de losas de piedra caliza bien talladas a modo de mesas de ofrendas, sin calzos y las cubiertas de tégulas, algunas tumbas, sobre todo infantiles, aparecen sin cubrir. Las fosas son rectangulares con base plana sin revestimiento aunque siete de ellas contenían dos losas verticales bien talladas y una que estaba totalmente revestida. Algunas de estas tumbas contenian ajuar; se trata de ajuares muy pobres: aretes, sortijas, brazaletes y alfileres, colgantes, hebillas, clavos, monedas, jarritas. La orientación de estas tumbas era N-S.

24 VAQUERIZO, D. et al.: «Almedinilla», Los pueblos..., I, p. 73.

25 Al parecer puede tratarse del mismo lugar en el que P. PARIS y A. ENGEL situaban una necrópolis de inhumación de época prerromana; el profesor VAQUERIzO no ha logrado localizar ésta y en cambio sí que ha localizado la que incluimos en el catálogo, por tanto o se trata de la misma necrópolis o hay una confusión en los topónimos, o se encuentra en otro lugar con el mismo nombre que también está en las cercanías. Vid:: VAQUERIzO, D.: Almedinilla, p. 17-18.

${ }_{26}$ VAQUERIzO GIL, D.: «Prospección arqueológica superficial en las cuencas de los ríos Almedinilla y San Juan», $A A A$, II, 1989, p. 106.

27 Carmona Berenguer, S.: «La necrópolis tardorromana de «El Ruedo», Almedinilla. Córdoba. $A A C, 1$, pp. 155-172; Idem, op. cit., p. 90 y ss.

28 VAQuerizo GIL, D.: «La villa romana de «El Ruedo" (Almedinilla, Córdoba)», A.E.A., 63, 1990, pp. 295-316; Idem: Almedinilla, pp. 65 y ss. 
En el área de la necrópolis aparecían tres zonas negruzcas que la autora denomina "zona de ofrendas» y junto a ellas se recuperaron entre otros objetos relacionados con el ritual funerario lucernas y silex. Se asocia a una vía de carácter secundario y la cronología se sitúa entre el siglos IV-V d.C. ${ }^{29}$.

\section{Almodóvar del Río}

- Sepulturas de inhumación situadas al O. de Almodóvar, en el km. 21 , en las proximidades de la casilla del ferrocarril ${ }^{30}$.

\section{Añora}

- Tumbas halladas en los alrededores del actual núcleo de población, al parecer fueron expoliadas ${ }^{31}$.

- Necrópolis de «La Losilla», a $3 \mathrm{~km}$. del pueblo y 4 ó 5 al NO de Pozoblanco ${ }^{32}$.

\section{Baena}

- Necrópolis en el Cerro de la Antigua asociada a una villa romana ${ }^{33}$.

- Sepulcro del Arroyo del Plomo ${ }^{34}$, situado a $3 \mathrm{~km}$. de Baena y $200 \mathrm{~m}$. al Norte de la carretera Baena-Valenzuela. Se descubrió el 3 de enero de 1838 por unos trabajadores. Se trata de un sepulcro abovedado en ladrillo, dentro del cual se hallaba una caja de plomo junto a la cual se encontraban dos vasijas de vidrio, un canutero de hueso cerrado a rosca, dos bolitas del tamaño de nueces con olor a azufre y un candil de barro con decoración a ambos lados del agujero central: una estrella y una media luna. En el interior de la caja estaba el esqueleto de un individuo orientado hacia el Norte 
y a ambos lados del mismo había dos vasijas de vidrio, y una moneda que según la descripción de Valverde y Perales podría tratarse de un bajo imperio de Constantino Magno. También señala este autor que en los alrededores se encontraron restos de unas construcciones de recreo (casa o finca). Según todos estos datos creemos que podría tratarse de un sepulcro perteneciente al dueño de una villa en cuyo terreno se hallaría el mismo.

- Tumbas descubiertas en el Cortijo de "Las Cribanas", a $500 \mathrm{~m}$. del mismo. Son de inhumación y en su interior se hallaron, en algunas de ellas, vasijas de cerámica común junto al cadáver ${ }^{35}$.

- Tumbas de inhumación descubiertas en el Cerro «Los Molinillos». Aparecieron ocho tumbas de las cuales cinco de ellas pertenecian a un monumento funerario. También apareció un sarcófago de piedra que procede de una cista cubierta por una losa ${ }^{36}$. Se asocia a una vía de carácter secundario y a un asentamiento o poblado ${ }^{37}$.

- Posible necrópolis en el Cortijo de «La Paloma», $18 \mathrm{Km}$ al N. del pueblo, en el camino de Castro a Porcuna, $750 \mathrm{~m}$. al W-SW ${ }^{38}$. Hoy desaparecida.

- En el margen derecho del río Guadalmoral, en terrenos de Revilla y frente a una casa de campo que pertenecía a las hijas de D. Alfonso Villarreal, se halló un sepulcro compuesto por grandes piedras berroqueñas labradas. La mayor de ellas servía de estela, rematada en semicírculo, al parecer con restos de inscripción ${ }^{3}$.

- Necrópolis posiblemente de época romana en el Cerro del Tejadillo ${ }^{40}$, situado en el cortijo de Padilla. Al parecer quedan escasos restos romanos abundando el material de época medieval. Parte de la necrópolis ha desaparecido. Se aprecian tumbas saqueadas que estuvieron construi-

35 Serrano Carrillo, J.-Morena lópez, J.A.: Arqueología inédita de Córdoba y Jaén. Córdoba, 1984, pp. 64-65, n. 41 .

36 Bernier, J.: Nuevos yacimientos..., pp. 28-29, lams. II y Ill. Morena López, J.A.: «Intervención arqueológica en la necrópolis norte de Los Molinillos (Baena, Córdoba)", $A A A$, III, 1991, pp. 127-130; Ídem: «El poblado la necrópolis N. del Cerro de Los Molinillos (Baena, Córdoba). Estado actual de la Investigación", BRAC, 126, pp. 159-191.

37 Carmona Berenguer, S.: op. cit., p. 90.

38 MORENA, J.A. et alli: Prospecciones arqueológicas en la Campiña de Córdoba, Córdoba, 1990, p. 30, n. $^{\circ} 39$.

39 Valverde y Perales, F.: Historia de la Villa de Baena, p. 74.

40 Serrano Carrillo, J.-Morena López, J.A.: op. cit., pp. 56-57, n. ${ }^{\circ} 26$. 
das con grandes losas de piedra labrada. Según referencias orales contenían ajuares consistentes en vasijas.

\section{Belalcázar}

- Posible necrópolis en las cercanías de la ermita de la Virgen de Gracia ${ }^{41}$.

Beimez

- Tumbas de inhumación halladas en el lugar conocido como "La Demesilla». Posiblemente se trate de una necrópolis ${ }^{42}$. Pero los restos aparecidos continúan sin estudiar.

- Tumba descubierta en la Aldea de Doña Rama en cuyo interior se encontraba una urna cineraria de vidrio protegida por una caja de plomo (posible tumba de incineración) ${ }^{43}$.

\section{Bujalance}

- Necrópolis en el Pago de la Alameda ${ }^{44}$.

- Posible necrópolis en los Caseríos "La Cruz", situados al NO. de Morente y al S. de la carretera nacional de Bujalance a El Carpio, sobre el margen derecho del Salado. El rito practicado fue la inhumación. Junto a los restos humanos también se encontraron numerosas tégulas romanas ${ }^{45}$.

- Tumba aislada que fue hallada en la Finca Nueva, en el km.7 de la carretera Villa del Río-Cañete a unos $50 \mathrm{~m}$. al S. del cortijo ${ }^{46}$.

- Necrópolis en el Cerro Tirador ${ }^{47}$.

41 A ella parecen pertenecer algunos epígrafes hallados en la zona. Ver infra números 165 , 166 y 167.

42 VAQueRizo, D.: «Bélmez», Los pueblos de Córdoba, l, p. 206.

43 Ibídem.

44 Idem, «Bujalance», Los pueblos de Córdoba, I, p. 267.

45 PONSICH: Implantation rural..., 1987, p. 41, n. ${ }^{\circ} 101$.

46 Ibíd., p. 39, n. $^{\circ} 86$.

47 VAquerizo, D.: «Bujalance», Los pueblos de Córdoba, I, p. 267. 
Cañete de las Torres

- Tumbas halladas en el Cortijo del Alamillo, a la izquierda del camino Cañete-Lopera, detrás de dicho cortijo. Al parecer estaban cubiertas con losas y carecían de ajuar funerario ${ }^{48}$.

- Necrópolis de "La Barrera», situada a $1 \mathrm{~km}$. al N. de Cañete, a la izquierda del camino a Villa del Río ${ }^{49}$. Se trata de tumbas cubiertas por tégulas.

- Tumbas descubiertas en el lugar conocido como «Callejón de los Moros», por la carretera Cañete-Villa del Río, en un camino situado a la derecha que lleva a Lopera, a $250 \mathrm{~m}$. Se trata de una serie de tumbas de inhumación que según parece contaban con un ajuar funerario consistente en espadas y vasijas colocadas a ambos lados de la cabeza. Hoy se encuentra sepultado ${ }^{50}$.

- Tumbas que fueron descubiertas en el "Cortijo de Caracuel», a 3 $\mathrm{km}$. de Cañete por la carretera N.324 Córdoba-Almería por Jaén, en el lado derecho de la carretera, en un montículo. Se encuentran a $1 \mathrm{Km}$ del yacimiento de «Prados de Doña Ana». Con bastante probabilidad se trata de inhumaciones sobre todo por los restos de losas que aparecen en la zona ya que hoy estas tumbas están destruidas ${ }^{51}$.

- Tumbas de inhumación halladas en la Fuente de la Cruz, situada a $4 \mathrm{~km}$. de Cañete, por la carretera de Cañete-Villa del Río ${ }^{52}$.

- Tumbas descubiertas en el paraje conocido como «Las Gavias», 6 $\mathrm{km}$. al S. de Cañete por la carretera Bujalance-Baena, a pocos metros del cruce de ésta con la carretera Cañete-Baena. Al parecer son muy antiguas pero no se especifica de qué época ${ }^{53}$.

- Tumbas descubiertas en el "Cerro de la Horca», a la izquierda del camino de Cañete a Córdoba, 1,5 km. W de Cañete. En este lugar se ha-

CAMCórdoba, II, p. 157.

Ibid., p. 160; MORENA, J.A.: «Informe preliminar...", p. 114 y «Aproximación al estudio del poblamiento...», p. 37.

so Ibíd., p. 157; MOREnA López, J.A.: «Informe preliminar...", p. 114.

51 CAMCórdoba, II, p. 161.

52 Jbíd., p. 158.

53 Ibíd, p. 162. 
llaron varios enterramientos de losas. En el interior el ajuar funerario estaba compuesto por vasijas situadas en la cabecera del cadáver ${ }^{54}$.

- Tumbas halladas en el Cortijo de «El Morón», al E. del mismo; al N. del km. 9 de la carretera Cruz de los Portales-Lopera, entre ésta y el arroyo Estremera. Se trata de tumbas de inhumación al parecer cubiertas por tégulas dispuestas en batería ${ }^{55}$.

- Tumbas, posiblemente todas de inhumación, descubiertas en el lugar conocido como Suspiro del Fraile, a $4 \mathrm{~km}$. al NE de Cañete hacia Lopera, a $750 \mathrm{~m}$. del camino ${ }^{56}$.

- Sepulturas halladas en el Cerro de los Términos, donde confluyen los límites de los términos municipales de Baena, Castro del Río y Cañete de las Torres. Aquí fueron halladas una serie de tumbas construidas con tégulas. También apareció el epigrafe funerario de lulia Pelagia (número 20) ${ }^{57}$.

- Restos de tumbas hallados en el lugar de «Torremocha», 10,5 km. SW de Cañete, por la carretera que va de Cañete-Castro ${ }^{58}$.

\section{Cardeña}

- Sepulcro hallado en Venta de Azuel ${ }^{59}$.

\section{La Carlota}

- Tumbas halladas en el Cerro Corriente, al N. del camino que lleva al cerro y al E. de la Chica Carlota, cerca de Suerte Zapatera. Se corresponden con la tipología de tumbas de Campana («a Caisson»). Son de inhumación ${ }^{60}$.

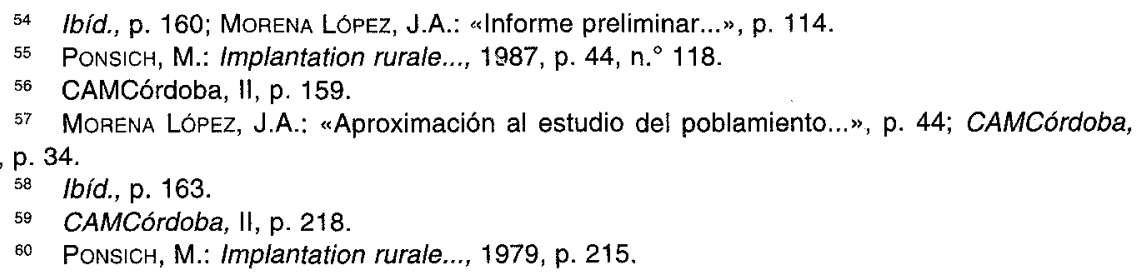

60 PONSICH, M.: Implantation rurale..., 1979, p. 215. 
- Tumbas descubiertas en el Cerro de la Fuente del Membrillar. En la zona también aparecieron restos de edificaciones, tumbas y fundición de hierro de época romana ${ }^{61}$.

- Necrópolis situada en la Loma de los Moros o de los Muertos, al S. de Fuente Membrillera, asociada con probabilidad a una villa romana ${ }^{62}$.

- Tumbas halladas en Las Pinedas (S.); en el antiguo lugar conocido como «Las Momias». Asociada a una villa datable en el siglo IV ${ }^{63}$.

\section{El Carpio}

- Necrópolis situada en la falda de la colina donde se situa el actual pueblo y en cuya cima se hallaría también el poblamiento antiguo ${ }^{64}$.

- Sepulturas encontradas en la finca de "La Huelga», al N. del Guadalquivir. Al parecer estos sepulcros estaban hechos a base de tegulae ${ }^{65}$.

\section{Castro del Río}

- Necrópolis El calvario (II), situada al NE de Castro, en el lado derecho de la carretera vecinal CV-149 de Castro a Cañete, lugar de la antigua ermita. En total se hallaron 10 tumbas, se trataba de pequeñas fosas simples, excavadas en la grava y cubiertas por losas de caliza ${ }^{66}$.

- Tumbas que fueron descubiertas en La Capilla, lugar situado $1 \mathrm{~km}$. al $\mathrm{W}$ de Castro, en el lado izquierdo del km. 44,7 de la carretera C-329 Montoro-Puente Genil. Aunque no quedan testimonios de las mismas, al parecer eran de inhumación ${ }^{67}$.

61 Godoy DelgaDo, F.: «Prospección arqueológica superficial de urgencia en el tramo CórdobaEl Carpio, correspondiente al proyecto de la Autovía de Andalucía”, $A A A, 111,1987$, p. 134.

62 VAQUeRIZO, D.: «La Carlota», Los pueblos de Córdoba, II, p. 404.

63 PONSICH: Implantation rurale..., 1979, p. 214.

64 VAquerizo, D.: «El Carpio», Los pueblos de Córdoba, II, p. 246.

65 lbídem.

66 Morena Lopez, J.A.: Prospecciones arqueológicas..., p. 80, n. ${ }^{\circ}$ 192. VAQUeRIzo, D.: «Castro del Río", Los pueblos de Córdoba Il, p. 450.

67 Morena López, J.A.: op. cit., p. 59, n. ${ }^{\circ} 118$. 
- En el Cortijo de Doña Mayor aparecieron abundantes restos humanos, podiendo tratarse de una necrópolis de inhumación ${ }^{68}$.

- Cortijo de las Salinas de Doña Esteban, a $5 \mathrm{~km}$. al N-NE de Castro aparecieron una serie de restos, hoy desaparecidos, que hicieron pensar en la existencia de una necrópolis ${ }^{69}$.

- Necrópolis de Guta (VI) ${ }^{70}$.

- Necrópolis descubierta en la Viña del Serrano o del Bononato ${ }^{71}$.

Córdoba T.M.

- Sepultura de inhumación hallada en el Cortijo de Alfayatas. Se trata de una fosa excavada en un estrato de gravas que estaba cubierta por losas de piedra caliza. El enterramiento presenta signos de reutilización ya que los restos de la primera inhumación se encuentran agrupados en uno de los extremos de la fosa. El cadáver aparece en posición decúbito supino y parece ser una persona adulta de unos $1,80 \mathrm{~m}$ de altura. Esta sepultura estaría asociada a una villa ${ }^{72}$, y se situaría en las proximidades de una vía principal ${ }^{73}$.

- Área de necrópolis en el Cortijo del Chancillerato, asociada a una villa, próxima a una calzada romana, hoy via pecuaria de opus caementicium ${ }^{74}$.

- Tumbas halladas en el Cortijo de Don Fernando, en el S. de la aldea moderna, en el punto de encuentro con el cortijo vecino de Florentino Ruiz Estera. Al parecer eran tumbas de inhumación que estaban cubiertas por tejas dispuestas en batería. Se han fechado en el siglo IV d.C. ${ }^{75}$.

- Tumbas halladas en el Cortijo de Nora del Cojo, en la ruta de Bujalance-Valenzuela, en la entrada del camino cercano al cortijo, al O. del mismo. Se trata de dos tumbas romanas, que se han situado en un nivel de ocupación perteneciente al siglos IV-V d.C. ${ }^{76}$. 
- Restos de una necrópolis romana en el Cortijo de Villa-Realejo. En este lugar se han hallado otros restos romanos como cerámica, monedas, restos de ánforas ${ }^{77}$.

\section{Doña Mencía}

- Sepulturas halladas en el lugar conocido como Benazar (Henazar - Genazar) durante las obras de construcción de un camino vecinal que va desde la estación de ferrocarril a la carretera Baena-Cabra. Se trata de tres tumbas de inhumación que se encontraban en muy mal estado de conservación dada la pobreza del material empleado. Los restos humanos aparecieron casi pulverizados; las cubiertas estaban constituidas por losas de arcilla o material blando, mezcladas con ladrillos. En el interior de una de ellas se halló un arete circular de cobre o bronce con un extremo agudo y otro romo. Al parecer también se encontró un anillo ${ }^{78}$.

- Necrópolis situada en el lugar conocido como Cruz de los Aguijones, a $1 \mathrm{~km}$. SO del pueblo, $300 \mathrm{~m}$. al O. del Henazar. Se hallaron restos de tumbas de tipo cista, cuyos cadáveres se encontraban en posición fetal ${ }^{79}$.

- Necrópolis de Dos Torres ${ }^{80}$.

- Posible necrópolis hallada en La Higueruela, camino viejo de Cabra a Baena, situada a $2 \mathrm{~km}$. al NO del pueblo. Se trata de varias cistas sobre roca en las que se empleó el ritual de la inhumación ${ }^{81}$.

- Necrópolis hallada en el Llano Medina, $1 \mathrm{~km}$. al $\mathrm{SO}$ del pueblo, separado del yacimiento de La Plata por el camino viejo de Luque. Se encuentra justo al lado del camino. Entre el ajuar funerario se destaca el hallazgo de una barrita de plata, posiblemente para la manicura y un arete en forma de serpiente ${ }^{82}$. Esta necrópolis se encontraría al borde del antiguo

77 Romero de TORRES, E.: “Córdoba. Nuevas antigüedades...», BRAH, 55, 1909, p. 489.

78 Noticia transmitida por el Secretario de Ayuntamiento e incluida en el N.A.H., III, 1953, 1-3, p. 213.

79 CAMCórdoba, III, p. 98

80 VAQUERIZO, D.: «Doña Mencía», Los pueblos de Córdoba, II, p. 497.

81 CAMCórdoba, III, p. 99.

82 Bernier, J.: Nuevos yacimientos..., p. 62. 
camino de Metedores que según Enrique Melchor no sólo mantuvo su importancia sino que se convirtió en vía pública ${ }^{83}$.

\section{Dos Torres}

- Sepulturas cercanas a Porcuna, al N. de Casa Matías Moreno. Las referencias que se tienen de las mismas las describen como sepulcros antiguos sin especificar ningún tipo de cronología ${ }^{84}$.

\section{Encinas Reales}

- Tumbas halladas en el lugar conocido como «Las Mesillas» ${ }^{85}$.

\section{Fernán-Núñez}

- Necrópolis del Pago de Mudapelo. Restos de lápidas ${ }^{86}$.

\section{Fuente Palmera ${ }^{87}$}

- Tumba hallada en el propio pueblo ${ }^{88}$.

83 MelChoR GIL, E:: «Doña Mencía», Los pueblos de Córdoba, p. 497; en este artículo el autor basa sus afirmaciones en el hallazgo de una serie de epígrafes, concretamente en un miliario y en una señalización de caminos donde se indica a los viandantes la dirección que deben tomar.

84 CAMCórdoba, Ill, p. 121.

85 MeLCHOR GIL, E.: «Encinas Reales», Los pueblos de Córdoba, II, p. 540.

86 CAMCórdoba, III, p. 226. También tenemos noticia del hallazgo de restos humanos en las cercanías de este lugar por Samuel de los Santos que incluyó una breve referencia al mismo en el N.A.H., II, 1953, 1-3, p. 214, donde, al parecer también se hallaron restos romanos como solería de ladrillo policromado, cinco metros de tubería de plomo, el lugar donde estuvo una fuente hexagonal de jaspe. Todo ello a unos $0,60 \mathrm{~m}$. de profundidad. Sobre el hallazgo de lápidas que menciona Bernier, Samuel de los Santos sólo hace referencia al hallazgo de una lápida con la inscripción PATRIAE P. MANLIUS P F PNC. Igualmente L. M. RAMiREZ y DE LAS CASAS-DEZA recoge en su obra Corografía histórico-estadiatica de la provincia y obispado de Córdoba, Córdoba, 1986, una serie de objetos encontrados en el lugar entre los cuales destacan además de los ya mencionados lucernas, mosaicos geométricos y jarros cerámicos.

${ }^{87}$ De este pueblo tenemos noticia del hallazgo de un sarcófago en el Molino de San José que según PONSICH en Implantation rurale..., 1979, p. 222, servía de abrevadero. Nosotros no lo hemos incluido en el catálogo pues se desconoce el lugar exacto del hallazgo.

88 CAMCórdoba, IV, p. 110. 

villa ${ }^{89}$.

- Necrópolis descubierta en Casa del Alcálde y asociada a una

\section{La Granjuela}

- Necrópolis hallada en el finca El Donadío Viejo. Parece asociarse a los restos de una villa ${ }^{90}$. En este lugar también se han hallado numerosas lápidas y varias inscripciones.

\section{Guadalcázar}

- Tumbas descubiertas al arrancar los olivos en Molino Alto, al O. del mismo ${ }^{91}$.

- Necrópolis descubierta en el Cortijo Reynilla. Se trata de una necrópolis de inhumación, con una ajuar bastante pobre consistente en dos vasijas de cerámica común situadas en la cabecera, una de ellas mientras la otra se colocó a la altura de la pelvis del cadáver; en otra tumba la difunta fue enterrada con los pendientes que presentaban forma de aretes y con una anillo que parece representar una serpiente. Pertenece al período tardorromano ${ }^{92}$, siglos IV-VII d.C.

\section{Hinojosa del Duque}

- Tumbas halladas en el lugar conocido como Los Lotes ${ }^{93}$.

89 VAQUeRIzO GIL, D.: «Fuente Palmera», Los pueblos de Córdoba, II, p. 682.

90 Idem, «La Granjuela», Los pueblos de Córdoba, III, p. 722.

91 PonsicH, M.: Implantation rurale..., 1979, 201.

92 Esta necrópolis fue objeto de una excavación de urgencia llevada a cabo por un equipo del cual formábamos parte, codirigido por los profesores Pedro J. LACORT NAVARRO y J.L. DEL. PINO GaRCía; el estudio de la misma se encuentra en prensa en el próximo n. ${ }^{\circ}$ (15) de la revista Ariadna.

93 CAMCórdoba, IV, p. 176. 


\section{Hornachuelos}

- Tumba de inhumación hallada en el Cortijo de Bramadero ${ }^{94}$.

- Necrópolis descubierta en el Castillo de la Alcarria, situado en el Cerrejón de la Alcarria. En el lugar se hallaron varios esqueletos y cerámica. Las dimensiones de estas tumbas eran aproximadamente de $40 \mathrm{~cm}$ $x 200 \mathrm{~cm}$ y $50 \mathrm{~cm}$ de profundidad. Posiblemente se trate de una necrópolis romana de inhumación ${ }^{95}$.

- Necrópolis de Aldefillas, situada en el paraje de Cabezas. En la zona fueron hallados varios cráneos y algunas lápidas. Posiblemente se trate de una necrópolis de inhumación ${ }^{96}$.

- Tumbas descubiertas en la Casa de las Caleras, situada en el llamado Cerro de las Tumbas al S. del cortijo. Se encuentran situadas en la zona nivelada. Una de estas tumbas se corresponde con la tipología de Campana «à Caisson» ${ }^{97}$.

- Necrópolis de Corregidora (E.); situada al E. de un camino que lleva a la ribera del Guadalquivir desde época prerromana ${ }^{98}$.

- Tumbas halladas al NE de Pedrejón, en el Cerro de Malverde, en la Alta. Son sepulcros de época romana ${ }^{99}$.

- Necrópolis de "El Ochavillo", situada en el extremo SE de una loma amesetada situada a unos $400 \mathrm{~m}$. al $O$. de la aldea de Céspedes. Se trata de una necrópolis de inhumación de época tardorromana (s. III-IV d.C.) cuya extensión real se desconoce ${ }^{100}$. La tipología de las sepulturas se reduce a fosas excavadas sin más en la tierra y a fosas excavadas en la tierra pero con paredes revestidas por lajas de piedra. Lajas que también aparecen como cubiertas en los casos en los que ésta existe, ya que hay otras sepulturas que carecen de ella. La orientación de estas tumbas es hacia el Este, manifestando una tendencia a formar hileras o calles. En

\footnotetext{
$94 \quad$ Ibid., IV, p. 246.

95 lbid., p. 242.

$96 \quad$ lbid., p. 241.

97 Ibid., p. 246.

$98 \mathrm{PONSICH}$, M.: Implantation rurale..., 1979, p. 233.

99 CAMCórdoba, IV, p. 241.

100 Vaquerizo Gil, D.: «Hornachuelos», Los pueblos de Córdoba, III, p. 797; Murillo REDONDO, J.F.: «Informe preliminar de la excavación arqueológica de urgencia en la necrópolis de "El Ochavillo" (Céspedes, Hornachuelos)", AAA, III, 1989, pp. 151-156.
} 
cuanto al ritual el cadáver fue colocado en posición extendida sobre su dorso, con el rostro hacia el Este y los brazos a los lados o sobre el pecho. Algunas de estas tumbas fueron reutilizadas encontrándose enterramientos dobles, triples y cuádruples, sobre todo, las infantiles. Los cadáveres debieron ser enterrados envueltos en un sudario puesto que, salvo en una de las tumbas, no se han hallado clavos En cuanto al ajuar parece bastante pobre a tenor de los datos incluidos en el informe de la excavación, se encontraron una jarrita piriforme de arcilla de cuello corto y labio con pico colocada junto a la cabeza del difunto; un vaso de vidrio situado a la derecha del difunto; un recipiente de bronce.

- Tumbas descubiertas en la separación entre la carretera de Palma y la Estación. El número total fue de 25 sepulturas de inhumación excavadas en la caliza ${ }^{101}$.

\section{Lucena}

- Necrópolis de Albarizas Bajas ${ }^{102}$. Posiblemente asociada a una villa pues en este mismo lugar se han encontrado capiteles, columnas y basas realizados en mármol de Cabra ${ }^{103}$. López Salamanca ${ }^{104}$ relaciona estos restos con la posible existencia de un templo dedicado al culto de Attis, basándose para ello en un mapa de García y Bellido, reproducido por J. Mangas ${ }^{105}$, en el que se sitúa un templo a Attis en Lucena.

- Necrópolis situada en el partido de Anjarón. Se trata de un conjunto de tumbas que al parecer pueden ponerse en relación con cuatro villae cercanas, ya que se situaría en un término medio entre ellas ${ }^{106}$. Las sepulturas carecían de ajuar funerario y estaban construidas con tégulas. Al parecer pudieron haberse practicado tanto el rito inhumatorio como el crematorio.

- Necrópolis de Baños de Horcajo ${ }^{107}$. También asociada a una villa, ya que se han hallado restos de unas termas, columnas capiteles, etc.

\footnotetext{
101 CAMCórdoba, IV, p. 243.

102 Melchor GIL, E.: «Lucena», Los pueblos de Córdoba, II, p. 855.

103 VAquerizo GIL, D.: «Lucena», Los pueblos de Córdoba, III, n. ${ }^{\circ} 43$, p. 855.

104 López Salamanca, F.: Historia de Lucena..., p. 52-53.

105 MANGAS, J.:»Religiones romanas y orientales", en Historia de España Antigua. II. Hispania romana. Madrid, 19883, pp. 625-661.

106 Lopez SalamancA, F.: Historia de Lucena..., pp. 78-80.

107 Jbídem.
} 
- Posible necrópolis ${ }^{108}$ situada en las proximidades de la confluencia del arroyo Martín González y el río Anzur, en el partido de Castilrubio. Al parecer, durante el desarrollo de las tareas agrícolas se pusieron al descubierto tégulas, ladrillos, trozos de jaspe y los restos de una lápida de mármol blanco decorada con molduras y bajorrelieves florales. Se asocia a una villa del siglo iv d.C.

- Tumbas aparecidas en la Iglesia del Colegio de la Purisima. Son sepulturas romanas de inhumación ${ }^{109}$.

- Tumbas halladas en «La Hoja», junto al posible trazado de la via Corduba-Anticaria, a $5 \mathrm{~km}$. de Monturque. Se trata de 12 tumbas de inhumación ${ }^{110}$.

- Necrópolis de Las Navas del Selpillar. Junto al arroyo Horcajo ${ }^{111}$. En las cercanías de la vía Corduba-Malaca, en el lugar conocido como "Los Santos". En este mismo lugar se halló un epígrafe en el que se marcaban las medidas del locus o espacio funerario (CIL, II, 1630). En 1980, al emprenderse las tareas de ampliación de la carretera, se pusieron al descubierto una serie de sepulturas que carecían de ajuar y presentaban cubierta de tégulas. Al parecer en 1986, en el momento de iniciarse la construcción de la carretera ya se encontraron varios sepulcros, aras, estatuas... ${ }^{112}$. Recientemente, se hallaron más tumbas, con orientación Norte-Sur, construidas de tégulas e ímbrices, cubiertas por losas de piedra; para López Salamanca, la existencia de restos de ánforas y otros recipientes de arcilla puede relacionarse con el rito de la incineración. En la zona se encontraron varias monedas iberorromanas y romanas. Se le atribuye al yacimiento una amplia cronología (siglos I a.C.-v d.C.).

- Sepulcro hallado en 1590, en él se contenían dos difuntos y, al parecer, la inscripción $n .^{\circ} 45$ de nuestro catálogo correspondería al mismo.

- Sepulturas halladas en la denominada Villa de los Silos ${ }^{113}$. Al parecer se trata de una serie de cubiertas en su mayoría con tégulas que ca-

\footnotetext{
108 López Salamanca, F.: Historia de Lucena..., p. 40.

109 CAMCórdoba, V, p. 76.

110 Lacort Navarro, P.J.: Monturque..., p. 54.

111 Melchor GIL, E.: «Lucena», Los pueblos de Córdoba, III, n. ${ }^{\circ} 43$, p. 855; CAMCórdoba, V, página 72. 54.

112 Lacort Navario, P.J.: Monturque..., p. 53; López Salamanca, F.: Historia de Lucena..., p. 113 López Salamanca, F.: Historia de Lucena..., p. 43.
} 
recen de ajuar funerario. También se han constatado cistas, consistentes en cántaros de boca ancha, sin asas y con las cenizas del difunto junto a vasos lacrimatorios de vidrio.

\section{Luque}

- Posible sepulcro al que podría haber pertenecido la inscripción $C I L$, II, 1601.

- Tumbas tardorromanas halladas al realizar las tareas de labranza en el lugar conocido como Nadel Alto. Se trata de sepulturas construidas con grandes losas de piedra. Contenían ajuar de carácter ritual consistente en jarritas de cerámica. Se asocian a una villa romana ${ }^{114}$.

\section{Montalbán}

- Necrópolis hallada en la Huerta de Tentecarretas. En el lugar aparecieron huesos humanos, lucernas, recipientes cerámicos, monedas (una de ellas de Honorio), joyas. Al parecer se trata de una necrópolis de inhumación que se fecha entre los siglos IV-V ${ }^{115}$.

\section{Montemayor}

- En el lugar conocido como Fuente Nueva se encuentra un sepulcro abovedado realizado en piedra y ladrillo dentro del cual se halló un sarcófago de plomo ${ }^{116}$.

- Necrópolis situada en el Cerro de la Horca. En este lugar aparecieron una serie de huesos calcinados, lo cual hace pensar en el rito de la incineración ${ }^{117}$.

- Necrópolis del Cortijo de Rayos ${ }^{118}$.

114 ARJONa CASTRO, A.: "Orígenes históricos de los pueblos cordobeses de la Subbética", BRAC, 113, 1987, pp. 89-111.

115 CAMCórdoba, VI, p. 65.

116 VAQUERIZO, D.: “Montemayor», Los pueblos de Córdoba, III, p. 953.

117 CAMCórdoba, VI, p. 97.

118 VAQUERIZO GIL, D.: «Montemayor», Los pueblos de Córdoba, III, p. 953. 
Montilla

- En el lugar conocido como el Cuadrado se han hallado varios restos de época romana que indican la existencia en la zona de una villa, entre dichos restos aparecieron unos sarcófagos ${ }^{119}$.

- Necrópolis descubierta en la estación de ferrocarril. En ella, al parecer, se han recogido algunas inscripciones ${ }^{120}$. Según $\mathrm{E}$. Melchor esta necrópolis estaría flanqueando la vía Corduba-Malaca ${ }^{121}$.

\section{Montoro}

- Tumbas halladas en Arroyo del Agua, al otro lado ${ }^{122}$, en la Loma de Lara situada a $9 \mathrm{~km}$. de la carretera Montoro-Adamuz.

\section{Monturque}

- Necrópolis de «Bolsa de Hierro» y Cortijo de «Las Majadas». Son dos áreas funerarias que se encuantran muy próximas a lugares donde aparecen restos de habitación rural de época romana ${ }^{123}$.

- Necrópolis de «Las Campiñuelas», según referencias orales parece que en el lugar aparecieron numerosas sepulturas todas elias de inhumación. También apareció en la zona un mosaico. Nosotros hemos podido comprobar que en el lugar hay numerosos restos de época romana entre ellos material de construcción como tegulae, ladrillos y fragmentos de losas y material cerámico destacando por su cantidad la cerámica comúm, la terra sigillata procedente de Andújar y la cerámica africana. Igualmente de este lugar proceden una serie de monedas de época hispanorromana y bajo imperia ${ }^{124}$.

\footnotetext{
1 t9 CAMCórdoba, VI, p. 135.

120 VAQUERIZO, D.: «Montilla», Los pueblos de Córdoba, III, p. 975.

121 MELCHOR GIL, E.: La red de comunicasiones romana en la provincia de Córdoba. Memoria de Licenciatura. Universidad de Córdoba. Córdoba, 1987, p. 176.

122 PONSICH, M.: Implantation rural..., 1987, p. 75.

123 Lacort Navarro, P.J.: Monturque..., p. 51.

124 Estas monedas pertenecen a una colección particular que en la actualidad estan siendo objeto de un estudio de investigación realizado por Raquel GIL FERNÁNDEZ a quien agradecemos tos datos que nos ha facilitado.
} 
- Necrópolis de la Herradora. Situada a unos 500 metros al NO del actual pueblo. Tenemos conocimiento de la existencia de esta necrópolis a través de referencias orales, según las cuales fueron descubiertos unos 20 ó 30 enterramientos, que presentaban una cubierta de losas a dos aguas, algunas de las cuales se emplearon como pavimentos en varias viviendas. También se recuperaron en la zona un conjunto de jarritas enteras que muy posiblemente formasen parte del ajuar ${ }^{125}$. El yacimiento en sí ha sido datado en torno al siglo III d.C. en adelante, aunque con reservas ${ }^{126}$.

- Tumba hallada en el Pago de «El Silillo», cerca del cortijo «El Cerrajero». Se trata de una construcción romana semisubterránea realizada en opus caementicium, de forma rectangular al exterior y abovedada en el interior. Se accede a la misma mediante una puerta adintelada situada en uno de los lados menores, en la pared opuesta hay un hueco cuadrangular rematado por un arco de medio punto. Según el cronista del pueblo, Francisco Luque, en el momento del hallazgo se encontraron en el interior del edificio restos humanos y un busto de mármol blanco que en la actualidad se halla desaparecido ${ }^{127}$. Según Pedro J. Lacort parece tratarse de un sepulcro, posiblemente la cámara funeraria del propietario de una villa situada en las inmediaciones de la misma.

\section{Obejo}

- Necrópolis situada en el lugar conocido como Pasá de Mahoma, en el arroyo de Obejo, cerca de la desembocadura del Guadalbarbo, al SO del Cortijo Majada de la Peña ${ }^{128}$. Al parecer es de inhumación.

\section{Palenciana}

- Necrópolis situada en el Cerro del Pozuelo. En el lugar se encontraron fragmentos de urnas y lápidas. En este lugar también se han halla-

125 Sobre el material hallado en la prospección del yacimiento que llevamos a cabo junto a Raquel GIL. Fernández, entre el que destaca un dado de hueso, ver: GIL FeRnández, R.: Aportaciones al conocimiento de la época romana en Monturque (Córdoba) y su entorno a través de una colección numismática. Memoria de Licenciatura (inédita). Córdoba, 1996.

126 Lacort Navarro, P.J.: Monturque..., p. 51.

127 lbíd., p. 47.

128 García Romero, José: “Obejo”, Los pueblos de Córdoba, IV, p. 1.116. 
do restos romanos posiblemente pertenecientes a una villa: tegulae, ladrillos y terra sigillata ${ }^{129}$.

\section{Palma del Río}

- Necrópolis situada en Barca de Calonge Bajo, en la ribera izquierda del Guadalquivir, en un cerro. Asociada a una villa del siglo IV ${ }^{130}$. También apareció en este lugar un sarcófago con signos de haber sido utilizado como abrevadero.

- Necrópolis de El Remolino ${ }^{131}$.

- Necrópolis hallada en el Cortijo de la Sesenta; en la ribera derecha de la Madre Vieja. Las tumbas se disponen en batería ${ }^{132}$.

Pedro Abad

- Posible necrópolis hallada en el Cortijo de la Higuera, $3,5 \mathrm{~km}$. al ESE por el camino de Villa del Río ${ }^{133}$.

\section{Pedroche}

- Tumbas halladas en los lugares conocidos como La Dehesa, El Boquerón, El Mohedano, El Ranchal, Cañada de la Viga y calle Real número $7^{134}$.

\section{Posadas}

- Sarcófago de piedra hallado en el Cortijo de la Estrella, al Norte de la aldea, en un codo del antiguo margen del Guadalquivir ${ }^{135}$.

\footnotetext{
129 VAQUerizo, D. y otros: «Palenciana», Los pueblos de Córdoba, IV, p. 1.134.

130 PONSICH, M.: Implantation rurale..., 1979, p. 110.

131 VAquerizo, D.: «Palma del Río», Los pueblos de Córdoba, IV, p. 1.150.

132 PONSICH, M.: Implantation rurale..., 1979, p. 62.

133 Morena, J.A.: Prospecciones arqueológicas, p. 122, $n .^{\circ} 298$.

134 García Romero, J.: "Pedroche", Los pueblos de Córdoba, IV, p. 1.207.

135 PONSICH, M.: Implantation rurale..., 1979, p. 165
} 
- Necrópolis hallada en la Huerta del Medrano, lugar en el que aparecieron numerosos restos humanos ${ }^{136}$.

- Necrópolis de La Mezquitilla. Asociada a una villa ${ }^{137}$. En este lugar se halló también la inscripción funeraria ClL, II, 2325.

\section{Priego de Córdoba}

- Restos de una necrópolis tardorromana hallados en Sierra Leones (formación montañosa), donde hay indicios de un asentamiento dominando el río Salado. Las características de las tumbas son las siguientes: aparecen enmarcadas mediante tegulae y losas de piedra caliza, cadáveres inhumados, se desconoce la existencia o no de ajuar ${ }^{138}$.

\section{Puente Genil}

- Sarcófago de mármol con decoración hallado en la zona de El Carril-Los Arroyos ${ }^{139}$.

- Necrópolis de Fuente Álamo ${ }^{140}$. Asociada a la villa ${ }^{141}$. En este lugar se han hallado abundantes restos que indican un hábitat romano pujante en el s. IV d.C., entre ellos varios mosaicos.

\section{La Rambla}

- Tumbas halladas en el lugar conocido como Casa de Lope. Se asocian a una villa romana ${ }^{142}$.

\footnotetext{
$136 \quad$ Ibíd, p. 148.

137 Ibídem.

138 VAQUERIZO, D.: «Prospección arquelógica superficial en el área de las Subbéticas Cordobesas. Fase I. 86», $A A A$, II, 1986, p. 94.

139 Idem, «Puente Genil», Los pueblos de Córdoba, IV, p. 1.362.

140 Ibidem.

141 Sobre la villa ver: CoRtıo CEREzo, Ma L.: «Puente Genil», Los pueblos de Córdoba, IV, p. 1364 y sobre todo LóPEz PALOMO, L.A.: «Excavación de urgencia en la villa romana de Fuente Alamo (Puente Genil, Córdoba). 1985». AAA, Ill, 1985, pp. 105-115.

142 VAQUERIZO, D.: «La Rambla», Los pueblos de Córdoba, IV, p. 1.411.
} 
- Necrópolis descubierta en el Cortijo del Ochavillo. Se trata de una necrópolis de inhumación en la que también aparecieron varios sarcófagos. Se fecha en el siglo IV d.C. ${ }^{143}$.

\section{Santa Eufemia}

- Necrópolis en el lugar conocido como Minas Viejas situado $6 \mathrm{~km}$. al Norte del pueblo, donde al parecer fueron hallados diversos restos entre los que se cuentan varias inscipciones.

\section{Santaella}

- Necrópolis situada en el Cerro de la Atalaya. Asociada a una villa ${ }^{144}$.

- Necrópolis de Las Canteruelas. Asociada a una villa ${ }^{145}$.

- Necrópolis hallada en el Cortijo del Guijarrillo. Aparece asociada a una villa ${ }^{146}$.

- Necrópolis descubierta en el Cortijo del Ingeniero. Asociada a una villa ${ }^{147}$.

- Necrópolis hallada en el Cortijo de Sahornil. Asociada a una villa ${ }^{148}$.

- Necrópolis situada en el Cerro de la Torre, $7 \mathrm{~km}$. al N. del pueblo, cerca de La Guijarrosa ${ }^{149}$. Se asocia a una villa, en la zona aparecieron abundantes restos de galerias de agua ${ }^{150}$. Se trata de una necrópolis de inhumación. Al parecer se hallaron ajuares de vidrio ${ }^{15 t}$.

\section{San Sebastián de los Ballesteros}

- Sepulcro hallado en 1817 en un edificio antiguo situado a un kilómetro del pueblo. A él pertenece la inscripción.

\footnotetext{
143 Ibidem.

144 Cortijo Cerezo, M⿻a L.: «Santaella», Los pueblos de Córdoba, V, p. 1.490.

145 Ibidem.

146 VAQUerizo, D.: “Santaella», Los pueblos de Córdoba, V, p. 1.488.

147 Cortiuo Cerezo, Mª L.: “Santaella», Los pueblos de Córdoba, V, p. 1.490.

148 Ibídem.

149 BerniER, J.: Nuevos yacimientos..., p. 82.

150 Cortijo Cerezo, M $M^{a}$ L.: «Santaella», Los pueblos de Córdoba, V, n. ${ }^{\circ}$ 59, p. 1.490.

i51 NAH, II, 1953, 1-3, p. 231.
} 
Villa del Río

- Necrópolis descubierta en el paraje conocido como el Arbol del Amor, a $1 \mathrm{~km}$. al $\mathrm{S}$. del pueblo, entre el camino Alto de Cañete a Villa del Río y el camino del Granadillo ${ }^{152}$.

- Necrópolis hallada en La Vega, al S. del Cortijo de la Veguilla y de la misma propiedad. Se fecha en el siglos IV-V ${ }^{153}$.

\section{Villanueva del Duque}

- Necrópolis situada en las cercanías de la Ermita de Nuestra Señora de Guía. De este lugar deben proceder algunas de las lápidas que se encuentran empotradas en la citada ermita.

\section{Villaralto}

- Necrópolis hallada en la Laguna de la Torrica o Cruz de Abraham, a $1 \mathrm{~km}$. de la villa. Asociada a un hábitat romano ${ }^{154}$.

\section{Zuheros}

- Sepulcro hallado en 1791 en el llamado Camino Real ${ }^{155}$. En él se encontraban los restos del difunto, en el interior de una urna, junto a un lacrimatorio y varias cuentas de piedra tosca.

152 Morena, J.A.: Prospecciónes arqueológicas..., p. 132, n. ${ }^{\circ} 313$.

153 Ponsich, M.: Implantation rurale..., 1987, p. 76, n. ${ }^{\circ} 29$.

154 Garcia Romero, J.: "Villaralto", Los pueblos de Córdoba, V, p. 1.720.

155 ARjona CAstro, A.: Historia de la villa de Zuheros y de la Cueva de los Murciélagos. Córdoba, 1991, pp. 33-35. 